Journal of Applied Pharmaceutical Science Vol. 2 (9), pp. 058-060, September, 2012

Available online at http://www.japsonline.com

DOI: $10.7324 /$ JAPS.2012.2912

ISSN 2231-3354 (cc) BY-NC-SA

\title{
Prophylactic effect of Andrographis pani culata extracts against fungal species
}

\author{
G.Rajalakshmi $^{1 *}$, D.Aruna ${ }^{1}$, B. Bhuvaneswari ${ }^{1}$, R.S. Venkatesan ${ }^{1}$, A.Natarajan ${ }^{2}$, K. Jegatheesan ${ }^{3}$ \\ ${ }^{1}$ Research Department of Biochemistry Adhiparasakthi College of Arts and Science, Kalavai- PIN- 632506, Vellore District, Tamilnadu, India. \\ ${ }^{2}$ PG \& Research Department of Zoology, C. Abdul Hakeem College, Melvisharam-632 509. Tamil Nadu, India. \\ ${ }^{3}$ Director, VI Institute of Technology, Chengalpet Taluk, Kanchipuram District- 603108, Tamilnadu, India.
}

\section{ARTICLE INFO}

Article history:

Received on: $18 / 08 / 2012$

Revised on: 29/08/2012

Accepted on: 05/09/2012

Available online: 28/09/2012

Key words:

A. paniculata,

antifungal activity,

test organisms.

\begin{abstract}
Andrographis paniculata (Acanthaceae) has been used to treat hepatoprotective, antidiarrhoeal, antiinflammatory, antimalarial, and antihypertensive. The aim of the study was to investigate the antifungal activity of different part of extracts of A. paniculata. The antifungal activity of extracts of $A$. paniculata was evaluated by Agar well diffusion method against five selected fungal species. Stem extracts of $A$. paniculata showed high antifungal activity against A.oryzae, Penicillum $s p$ and C.albicans. The root extracts showed high antifungal activity against A. niger, A. flavus, C.albicans, Penicillum $s p$ and A.oryzae and also leaf extracts showed high antifungal activity against Penicillum $s p$ and A. flavus but did not show antifungal activity against C.albicans, A. niger, A.oryzae. The results obtained in the present study suggest that $A$. paniculata plant can be used in treating various diseases caused by the test organisms.
\end{abstract}

\section{INTRODUCTION}

Medicinal plants are widely used for treatment of diseases all over the world. According to WHO report about $80 \%$ of the world populations are taking interest in indigenous medicinal plants remedies. Herbal medicines have usually been used in the form of fruit and vegetables, drugs or their extract for the treatment of the diseases and for maintenance health (Sahito $e t$ al., 2003). Skin disease, diarrhea, diabetes, malaria, respiratory infection, fungal and bacterial infection are the common health problem in rural areas. In under developing countries numerous medicinal plants are used traditionally which are remedial against these disease (Pinn, 2000). Fungal diseases cause significant loss in many important vegetable crops and plants. Many fungi are harmful as they are pathogens of plants, animals and human

\footnotetext{
* Corresponding Author
}

Adhiparasakthi College of Arts and Science, Kalavai,

Vellore District, Tamilnadu, India; Tel: +91-8870690296 beings or produce metabolites that are toxic to plants and animals (Richard et al., 1993; Bowers and Locke, 2000). Pathogenic fungi are the main infectious agents in plants, causing alterations during developmental stages including post-harvest. In fruit and vegetables, there is a wide variety of fungal genera causing quality problems related to nutritional value, organoleptic characteristics, and limited shelf life (Agrios, 2004). In addition, in some cases fungi are indirectly responsible for allergic or toxic disorders among consumers because of the production of mycotoxins or allergens. Andrographis paniculata Nees (Acanthaceae), commonly known as Nilavembu is an annual herb. It is found in wild throughout the plains of India especially in Tamil Nadu, Karnataka, Maharashtra, Maharashtra, Orissa and Uttar Pradesh. Some recent researcher reported on these plant having medicinal properties like antidiarrhoeal, anti-inflammatory, choleretic, antimalarial, antihypertensive, antipyretic, antithrombotic, antidote and hepatoprotective. 
The bioactive compound andrographolide has been reported to be effective in the treatment of upper respiratory tract infection (Gupta et al., 1990; Yin and Guo, 1993; Chturvedi et al., 1983; Chang and But, 1986; Hancke et al., 1995; Melchior et al., 1997; Melchior et al., 2004; Thamlikitkui et al., 1991; Poolsup et al., 2004; Coon and Ernst, 2004).

\section{MATERIALS AND METHODS}

\section{Plant Material}

Andrographis paniculata was collected from Adhiparasakthi Agriculture and Horticulture College, G.B. Nagar, Kalavai, Vellore District, Tamilnadu, India. Professor V. Durai authenticated the sample. Voucher specimen of the same was maintained in Adhiparasakthi Agriculture and Horticulture College.

\section{Plant extract preparation}

The collected plant materials were chopped into small pieces separately, shade-dried, at room temperature for 15 days (Mukherjee, 2002). Then coarsely powered using pulverizes. The coarse powders were subjected to successive extraction with organic solvent such as ethanol by soxhlet apparatus. The extracts were collected and distilled of on a water bath at atmospheric pressure and the last trace of solvents was removed in vacuum. The resulted extracts were used for antibacterial studies (Rammohan Subramanian et al., 2008).

\section{Test Organisms}

The test organisms used were Candida albicans (MTCC 10231), Aspergillus niger (MTCC 16404), Aspergillus oryzae (MTCC 42149), Aspergillus flavus (MTCC 9643), Penicillium species (MTCC 9480). All the stock cultures were obtained from Microbial Type Cell Culture (IMTECH, India).

\section{Culture Media and Inoculums Preparation}

Sabouraud dextrose agar /broth (Himedia, India.) were used as the media for the culturing of fungal strains. Loops full of all the fungal cultures were inoculated in the Sabouraud dextrose broth (SDB) at $37^{\circ} \mathrm{C}$ for $72 \mathrm{hrs}$.

\section{Reference drug}

Fluconazole was purchased from Biochem pharmaceutical industries Ltd., Mumbai. 30mg dissolved in $1 \mathrm{ml}$ with distilled water.

Antifungal activity study

Antifungal activities of the A. paniculata extracts viz. ethanol were determined, using the agar well diffusion assay method (Perez et al., 1990). Approximately $20 \mathrm{ml}$ of molten and cooled media (SDA) was poured in sterilized petri dishes. The plates were left overnight at room temperature to check for any contamination to appear. The fungal test organisms were grown in Sabouraud dextrose broth for $24 \mathrm{~h}$. A $100 \mathrm{ml}$ Sabouraud dextrose broth culture of each fungal organism $(1 \times 105 \mathrm{cfu} / \mathrm{ml})$ was used to prepare fungal lawns. Agar wells of $5 \mathrm{~mm}$ diameter were prepared with the help of a sterilized stainless steel cork borer. Five wells were prepared in the agar plates. The wells were labeled as A,B,C,D,E 'A' well was loaded with $20 \mu \mathrm{l}$ of solvent, 'B' well was loaded with $20 \mu \mathrm{l}$ of leaf extracts, C' well loaded with $20 \mu \mathrm{l}$ of stem extracts, D' well loaded with $20 \mu \mathrm{l}$ of root extracts and ' $E$ ' well loaded with $20 \mu \mathrm{l}$ of positive control drug fluconazole. The plates containing the fungal and plant extracts were incubated at $37^{\circ} \mathrm{C}$. The plates were examined for evidence of zones of inhibition, which appear as a clear area around the wells (Cheesbrough, 2000). The diameter of such zones of inhibition was measured using a meter ruler and the mean value for each organism was recorded and expressed in millimeter.

\section{RESULTS}

The present study the antifungal activity of seed extracts viz. leaf, stem and root were evaluated against five fungal $\mathrm{sp}$ (Table 1). In the first stage, leaf, stem and root plant extracts of Andrographis paniculata applied on one isolate of each fungal species. Stem extract of Andrographis paniculata showed significant antifungal activity against $A$. oryzae, Penicillium sp and C.albicans. The root extracts was recorded significant antifungal activity against $A$. niger, A.flavus, Penicillium sp, C.albicans and A.oryzae on the other hand the leaf extracts revealed significant antifungal effect on Penicillium sp and A.flavus but did not show same on C.albicans, A.niger, A. oryzae. The inhibitory activities of all the three extracts of the plant reported in the present study were compared with standard drug.

\section{DISCUSSION}

Antifungal activities of various herbs and spices in plant leaves, flowers, stems, roots, or fruits have been reported by many workers (Mau et al., 2001). Successful prediction of botanical compounds from plant material is largely dependent on the type of solvent used in the extraction procedure. In the present study three extract viz. leaf, stem and root were used for extraction. The antifungal activity was significantly recorded in stem and root extracts. This might be due to the better solubility of the active

Table. 1: Antifungal activity of different extract of Andrographis paniculata.

\begin{tabular}{|c|c|c|c|c|c|c|}
\hline \multirow{2}{*}{ S.No } & \multirow{2}{*}{ Samples } & \multicolumn{5}{|c|}{ Zone of inhibition in $\mathrm{mm}$} \\
\hline & & C.albicans & A. niger & A.oryzae & A. flavus & Penicillum sp \\
\hline 1 & Control & 03 & 0 & 02 & 03 & 05 \\
\hline 2 & Leaf & 08 & 07 & 09 & 15 & 17 \\
\hline 3 & Stem & 12 & 09 & 14 & 08 & 13 \\
\hline 4 & Root & 16 & 18 & 15 & 17 & 16 \\
\hline 5 & Fluconazole & 19 & 21 & 19 & 21 & 20 \\
\hline
\end{tabular}


components in the organic solvents (De Boer et al., 2005). The results obtained in the present study, wherein the leaf extracts revealed antifungal effect on only Penicillium $s p$ and A.flavus (Figure 1), when compared to stem (A. oryzae, Penicillium sp and C.albicans) root (A.niger, A.flavus, C.albicans and Penicillium sp) plant extracts this would supplement the above observation. The root extract revealed higher degree of antifungal activity for five fungal spp (C.albicans, A.niger, A.flavus, A. oryzae and Penicillium $s p$ ) out of five tested. However stem extract's antifungal efficacy was on A. oryzae, Penicillium $s p$ and C.albicans revealing that it is less potent compared with that of root extract. The therapeutic value of medicinal plants lies in the various chemical constituents presents it. The bioactivity of plant extracts was attributed to phytochemical constituents.

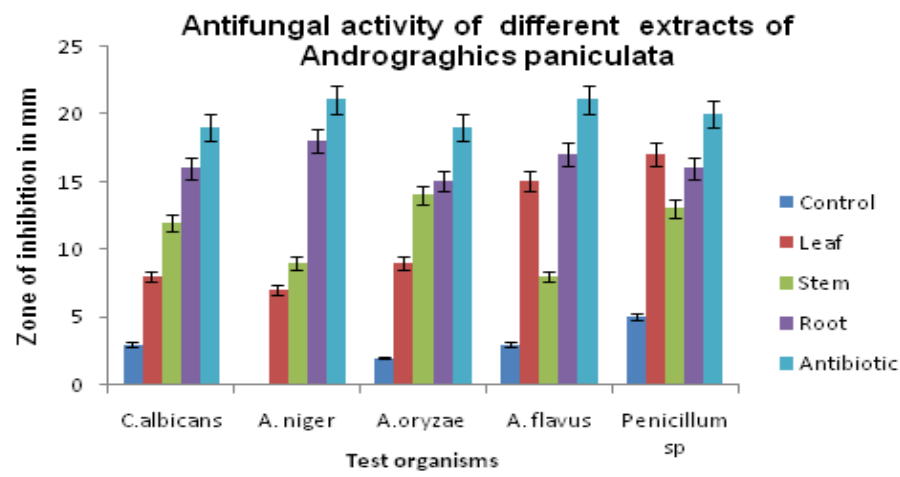

Fig. 1: Antifungal activity of different extract of Andrographis paniculata

\section{CONCLUSION}

Traditional medicinal plants Andrographis paniculata plant extract (root) revealed higher degree of antifungal potency against five fungal species tested. Further studies are required to isolate, identify and elucidate the structure of the bioactive compound.

\section{REFERENCES}

Agrios G.N. Losses caused by plant diseases. Plant Pathology. Elsevier, Oxford, UK. 2004; 29-45.

Bowers J.H., Locke J.C. Effect of botanical extracts on the population density of Fusarium oxysporum in soil and control of Fusarial wilt in the greenhouse. Plant Dis. 2000; 84(3): 300-305.

Chang H. M., But P.H. Pharmacology and applications of Chinese material medica. Singapore, World Scientific 1986; 1: 918-928.

Cheesbrough M. District Laboratory Practice in Tropical Countries. Low price edition. The press syndicate of the University of Cambridge, Trumpington Street Cambridge part 2. 2000; 157-206.
Chturvedi G., Tomar G. S., Tiwart S. K., Singh K. P. Clinical studies on Kalmegh (Andrographis paniculata Nees) in infective hepatitis. J. Internat. Institutions. Ayurveda. 1983; 2: 208-211.

Coon J. T., Ernst E. Andrographis paniculata in the treatment of upper respiratory tract infections: A systematic review of safety and efficacy. Planta Med. 2004; 70: 293-298.

De Boer H.J., Kool A., Broberg A., Mziray W.R., Hedberg I., Levenfors J.J. Antifungal and antibacterial activity of some herbal remedies from Tanzania. J. Ethopha. 2005; 96: 461-469.

Gupta S., Choudhry M. A., Yadava J. N. S. Antidiarrioeal activity of diterpenes of Andrographis paniculata (Kal-Megh) agent Escherichia coli enterotoxin in vivo models. Intl. J. Crude Drug Res, 1990; 284: 273-283.

Hancke J., Burgos R. A., Caceres D. D. A double-blind study with a new monodrug kan jang: Decrease of symptoms and improvement in the recovery from common colds. Phytother. Res. 1995; 9: 559-562.

Mau J.L., Chen C.P., Hsieh P.C. Antimicrobial effect of extracts from Chinese chive, cinnamon, and corni fructus. J. Agric. Food Chem. 2001; 49: 183-188.

Melchior J., Palm S., Wikman G. Controlled clinical study of standardized Andrographis paniculata extract in common cold - a pilot trial. Phytomedicine. 1997; 3: 315-318.

Melchior J., Spasov A. A., Ostrovskij O. V., Bulanov A. E., Wikman G. Double-blind, placebo controlled pilot and phase-III study of activity of standardized Andrographis paniculata Herba Nees extract fixed combination (Kan jang) in the treatment of uncomplicated upperrespiratory tract infection. Phytomedicine. 2004; 7: 341-350.

Mukherjee P.K. Quality control of herbal drugs, 1st ed. Business Horizons Pharmaceutical Publishers, New Delhi. 2002; 701.

Perez C., Paul M., Bazerque P. Antibiotic assay by agar well diffusion method. Acta Biol. Med. Exp. 1990; 15: 113-115.

Pinn G. Herbal medicine, an overview. Australian, Family Physician. 2000; 29(11): $1059-1062$.

Poolsup N., Suthisisang C., Prathanturarug S., Asawamekin A., Chanchareon U. Andrographis paniculata in the symptomatic treatment of uncomplicated upper-respiratory tract infection: Systematic review of randomized controlled trials. J. Clin. Pharm. Ther. 2004; 29: 37-45.

Rammohan Subramanian., Mohd. Zaini Aswani., Amirin Sadikum. Effect of Ethanolic Extract of A.P nees on a combination of fat fed Diet and low dies dose streptogotocin induced chronic insulin wesistance in rats. 2008.

Richard J.L., Bennet G.A., Ross P.F., Nelson P.E. Analysis of naturally occurring mycotoxins in feedstuffs and food. J Anim Sci. 1993; 71: 2563-2574.

Sahito S.R., Memon M. A., Kazi T.G., Kazi G.H. Evaluation of mineral contents in medicinal plant Azadirachta indica (neem). J. Chem. Soc. Pak. 2003; 25(2): 139-143.

Thamlikitkui V., Dechatiwongse T., Theerapong S. Efficacy of Andrographis paniculata Nees for pharyngotonsillitis in adults. J. Med. Assoc. Thailand. 1991; 74: 437-442.

Yin J., Guo L. Contemporary traditional Chinese medicine. Berijing, Xie Yuan, 1993.

\section{How to cite this article:}

G.Rajalakshmi, D.Aruna, B. Bhuvaneswari, R.S. Venkatesan, A.Natarajan, K. Jegatheesan. Prophylactic effect of Andrographis paniculata extracts against fungal species J App Pharm Sci. 2012; 2(9): 058-060. 